\title{
MÉTODO MÃE CANGURU NOS HOSPITAIS / MATERNIDADES PÚBLICOS DE SALVADOR E ATUAÇÃO DOS PROFISSIONAIS DA SAÚDE NA SEGUNDA ETAPA DO MÉTODO
}

\section{Kangaroo mother method in hospitals / public maternity in Salvador and performance of health professionals in the second stage of the method}

\author{
Juliana Rodrigues da Silva ${ }^{(1)}$, Célia Regina Thomé ${ }^{(2)}$, Renata Mathias de Abreu ${ }^{(3)}$
}

\begin{abstract}
RESUMO
Objetivo: investigar quantos hospitais/ maternidades públicos em Salvador utilizam o método mãecanguru, quais os profissionais estão inseridos na equipe e caracterizar a atuação dos profissionais de saúde que estão inseridos na segunda etapa do método. Método: trata-se de um estudo quantitativo descritivo do qual participaram os responsáveis pelo setor de neonatologia e os profissionais de saúde inseridos na segunda etapa do método respondendo a questionários. Os dados obtidos foram analisados por meio de estatística descritiva calculando-se frequências simples. Resultados: das sete instituições públicas de Salvador quatro utilizam o método. Nas três instituições pesquisadas realizam-se as três etapas preconizadas, em duas delas o quadro profissional tem pelo menos um atuante de cada especialidade recomendada pelo Ministério da Saúde, no entanto evidencia-se reduzido número de fonoaudiólogos nos serviços. Dentre as principais ações dos profissionais da saúde inseridos na segunda etapa estão o incentivo ao posicionamento canguru, ao aleitamento materno exclusivo e orientação às mães quanto aos cuidados com o bebê. Conclusões: evidencia-se que a recomendação do Ministério da Saúde de que o método seja implantado nas unidades médicoassistenciais integrante do Sistema Único de Saúde ainda não é uma realidade em todos os hospitais/ maternidades públicos de Salvador, no entanto evidenciou-se quadro profissional em conformidade com a recomendação em duas das instituições pesquisadas e a atuação dos profissionais entrevistados se incorpora no campo da transdisciplinaridade.
\end{abstract}

DESCRITORES: Hospitais; Maternidades; Neonatologia

\section{INTRODUÇÃO}

O Método Mãe Canguru (MMC), também conhecido como "Cuidado Mãe Canguru" ou ainda "Contato Pele a Pele", vem ganhando espaço na atualidade como uma alternativa ao cuidado

(1) Fonoaudióloga do Hospital João Alves Filho, Salvador, Bahia; Graduada em Fonoaudiologia pela Universidade Federal da Bahia.

(2) Fonoaudióloga; Professora do Departamento de Fonoaudiologia da Universidade Federal da Bahia; Mestre em Fonoaudiologia pela Pontifícia Universidade Católica de São Paulo.

(3) Fonoaudióloga da Maternidade Climério de Oliveira, Salvador, Bahia; Mestre em Fonoaudiologia pela Pontifícia Universidade Católica de São Paulo.

Conflito de interesses: inexistente neonatal que convencionalmente era destinado aos bebês de baixo peso ao nascer. O método foi idealizado e implantado inicialmente por Edgar Rey Sanabria e Hector Martinez em 1979, no Instituto Materno-Infantil de Bogotá, Colômbia. Recebe tal nomenclatura devido à maneira pela qual as mães carregam seus bebês após o nascimento, de forma semelhante aos marsupiais ${ }^{1}$.

Por meio do contato pele a pele espera-se que haja um vínculo mãe e filho muito maior, que auxilie no desenvolvimento psicomotor dos recém-nascidos, notadamente os de baixo peso, e promova o aleitamento materno².

Um dos principais objetivos do método é suprir a insuficiência de recursos materiais no cuidado com os prematuros, sendo usado assim como alter- 
nativa à substituição de incubadoras e evitando a separação prolongada entre a mãe e seu bebể ${ }^{3}$.

Medidas que melhorem a qualidade da assistência a esses recém-nascidos prematuros são cada vez mais cotadas, visando diminuir complicações futuras. É neste sentido que o Método Canguru apresenta inúmeros benefícios para o recém-nascido pré-termo de baixo peso e sua família, constituindo-se em recomendação de organizações científicas e governamentais para a assistência integral e humanizada em unidade neonatal ${ }^{2}$.

Ao longo das últimas décadas, diversos serviços adotaram o MMC, em países desenvolvidos e em desenvolvimento, evidenciando desta maneira a possibilidades de adaptação da proposta em diferentes contextos de acesso à tecnologia na assistência neonatal. No Brasil, por exemplo, os primeiros serviços que aplicaram o MMC foram o Hospital Guilherme Álvaro, em Santos (SP), em 1992, e o Instituto Materno-Infantil de Pernambuco (IMIP), em 19931.

Em nosso país há atualmente uma preocupação voltada para a problemática da assistência humanizada à criança e à família, em função dos avanços tecnológicos que vêm aumentando a sobrevivência e perspectivas de desenvolvimento de recém nascidos prematuros ${ }^{3,4}$. Assim, a adoção das Normas de Atenção Humanizada ao Recémnascido de Baixo-Peso (Método Canguru) representa um importante passo na promoção de uma mudança institucional centrada na humanização do cuidado em saúde para a família.

$\mathrm{O}$ atendimento perinatal tem sido foco das atenções do Ministério da Saúde, já que neste componente, juntamente com o pré-natal, reside o maior desafio para a redução da mortalidade infantil. Neste sentido, o Ministério da Saúde, pela Portaria GM/MS № 072 de 02 março de 2000, recomenda e incentiva a Atenção Humanizada ao Recémnascido de Baixo Peso, por meio do MMC, em todas as unidades médico-assistenciais integrantes do Sistema Único de Saúde (SUS), propondo a aplicação do método em três etapas².

A 1a etapa, realizada nas unidades de terapia intensiva neonatal (UTIN), é o período de adaptação e treinamento, onde a família recebe orientações quanto aos cuidados a serem realizados com as crianças, e a mãe recebe orientação quanto aos cuidados pessoais, e a posição canguru pode começar a ser realizada a depender do quadro clínico do bebê. $\mathrm{Na} 2^{\mathrm{a}}$ etapa o recém-nascido encontra-se estabilizado e poderá ficar com acompanhamento contínuo de sua mãe na enfermaria conjunta onde a posição-canguru será realizada pelo maior tempo possível. A $3^{\circ}$ etapa consiste no acompanhamento ambulatorial (Follow up) no qual há continuidade à assistência ao recém-nascido prematuro de baixo peso após a alta hospitalar².

Mesmo diante da recomendação do Ministério da Saúde e dos benefícios do Método Mãe Canguru na assistência ao recém-nascido de baixo peso, atualmente não se têm estudos evidenciando a utilização do método nos hospitais / maternidades de Salvador, nem mesmo relatando as práticas dos profissionais de saúde inseridos no método das instituições locais. Assim justifica-se a relevância do presente estudo que tem o objetivo de investigar quantos hospitais/ maternidades públicos em Salvador utilizam o método mãe-canguru, quais os profissionais estão inseridos na equipe e caracterizar a atuação dos que estão inseridos na segunda etapa do método nesta cidade.

\section{MÉTODO}

Trata-se de um estudo quantitativo descritivo observacional realizado por meio de um levantamento de dados dos hospitais / maternidades públicos de Salvador e de questionário aos profissionais de saúde inseridos na segunda etapa do método.

Dos quatro hospitais/ maternidades públicos de Salvador que possuem o método só foi possível coletar os dados em três deles devido ao atraso no tempo de liberação do comitê de ética.

Os responsáveis pelo setor de neonatologia responderam ao questionário (Figura 1), referente ao quadro de profissionais da instituição que atuam no método e sobre as características do mesmo na instituição, já os profissionais de saúde inseridos na segunda etapa responderam ao questionário referente às práticas realizadas no método (Figura 2).

Este estudo foi aprovado pelo Comitê de Ética em Pesquisa (parecer/resolução no 076/2009). Os participantes dessa pesquisa assinaram um termo de consentimento livre e esclarecido.

Os dados obtidos foram analisados por meio de estatística descritiva calculando-se freqüências simples, os mesmos foram tabulados no programa Microsoft Office Excel 20035.

\section{RESULTADOS}

Dos sete hospitais/maternidades públicos de Salvador, até o presente momento, quatro utilizam o método mãe canguru, segundo dados da Secretaria da Saúde do Estado da Bahia ${ }^{6}$. Segue abaixo a descrição da composição do método em cada instituição pesquisada: 


\section{QUESTIONÁRIO PARA INSTITUÇÕES № ORDEM \begin{tabular}{|l|l|l|l|}
\hline & & & \\
\hline
\end{tabular}}

\section{BLOCO I - Destinado ao responsável pela maternidade}

1. Nesta maternidade é utilizado o método mãe canguru?

( ) SIM (passe para o item 2) ( ) NÃO (obrigada pela participação)

2. Há quanto tempo este método é utilizado?

( ) 0-1 ano ( ) 1-2 anos ( ) 2-3 anos ( ) 4-5 anos ( ) mais de 5 anos

3. Quais as etapas do método são realizadas?

4. Quantos leitos há na enfermaria canguru?

5. No espaço abaixo preencha de acordo com os profissionais de saúde que compõem a equipe do método mãe canguru.

\begin{tabular}{|l|l|l|l|}
\hline PROFISSÃO & $\begin{array}{c}\text { NÚMERO DE } \\
\text { PROFISSIONAIS }\end{array}$ & VÍNCULO & $\begin{array}{c}\text { EM QUE ETAPA DO } \\
\text { MÉTODO ESTÁ } \\
\text { INSERIDO }\end{array}$ \\
\hline Neonatologista & & & \\
\hline Obstetra & & & \\
\hline Pediatra & & & \\
\hline Oftalmologista & & & \\
\hline Enfermeiro & & & \\
\hline Auxiliar de enfermagem & & & \\
\hline Psicólogo & & & \\
\hline Fisioterapeuta & & & \\
\hline Terapeuta ocupacional & & & \\
\hline Assistente social & & & \\
\hline Fonoaudiólogo & & & \\
\hline Nutricionista & & & \\
\hline Outros: & & & \\
\hline
\end{tabular}

Nome do entrevistado:

Telefone para contato:

Entrevista realizada em: 1

Figura 1 - Questionário para as Instituições

- Instituição A: O método é aplicado há mais de cinco anos, são realizadas as três etapas e a enfermaria canguru possui cinco leitos.

- Instituição B: O método é aplicado há mais de cinco anos, são realizadas as três etapas e a enfermaria Canguru possui dez leitos.

- Instituição C: O método é aplicado há quatro anos, são realizadas as três etapas, sendo que a $2^{\circ}$ e $3^{\circ}$ etapa estão mais estruturadas em relação à $1^{\circ}$ etapa. A enfermaria Canguru possui quatro leitos.
Em cada instituição um profissional de saúde de cada especialidade atuante na segunda etapa do método respondeu ao questionário. No entanto, alguns profissionais não puderam participar da pesquisa por estar de licença maternidade ou afastado temporariamente do cargo por questões de saúde. No total 21 profissionais foram entrevistados, sendo nove da instituição $A$, seis da $B$ e seis da C (Figuras 3 e 4). 


\section{QUESTIONÁRIO PARA OS PROFISSIONAIS}

1. Cargo do entrevistado:

2. Há quanto tempo trabalha com o método mãe canguru?

3. Há quanto tempo está formado na área da saúde?

4. Possui curso ou capacitação na área de cuidados com bebê? ( ) SIM ( ) NÃO

Nas próximas questões responda SIM caso realize tal ação ou responda NÃO se não as realiza.

\section{PERGUNTAS}

5. Orienta as mães quanto aos cuidados realizados com o bebê?

6. Orienta as mães quanto aos cuidados pessoais?

7. Ressalta os benefícios da amamentação exclusiva?

8. Favorece a participação do pai e/ou familiares na dinâmica dos cuidados pertinentes ao método?

9. Avalia a evolução da função de alimentação?

10. Estimula a sucção não-nutritiva?

11. Estimula a sucção nutritiva?

12. Encaminha para avaliações complementares aqueles que necessitarem de tratamento especializado?

13. Encaminha para realização de triagem auditiva neonatal?

14. Avaliação do estado de consciência e sinais de stress?

15. Descreva abaixo as ações que realiza em sua rotina diária no método mãe canguru:
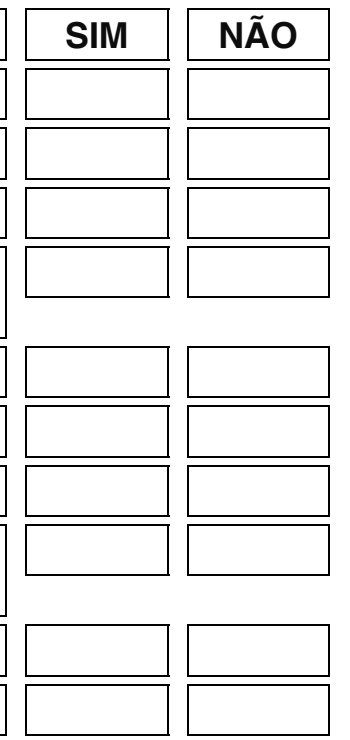

Nome do entrevistado:

Telefone para contato:

Entrevista realizada em:

Número:

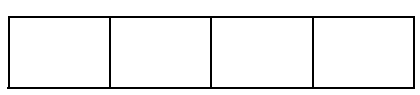

Figura 2 - Questionário para os Profissionais 


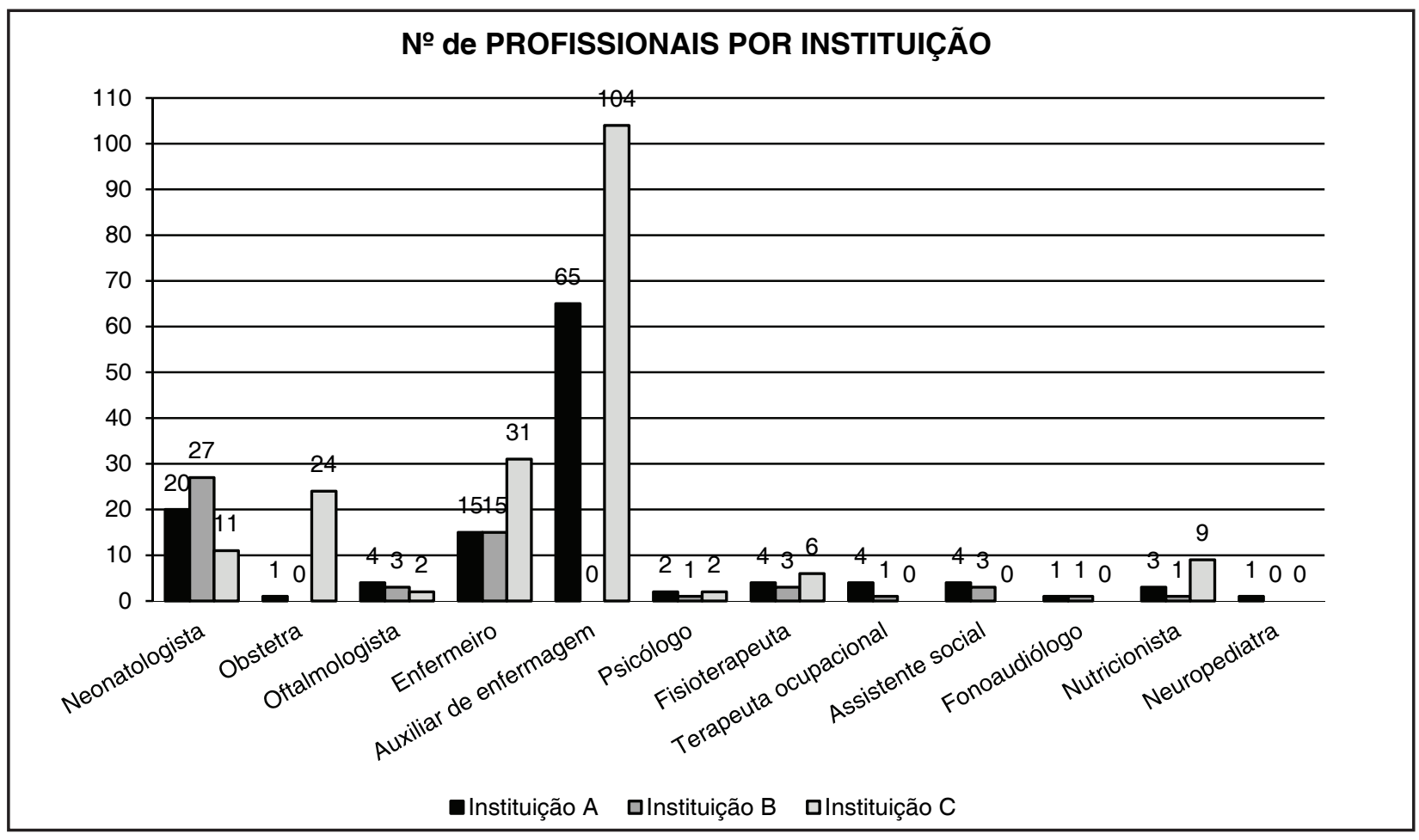

Figura 3 - Quadro profissional comparativo

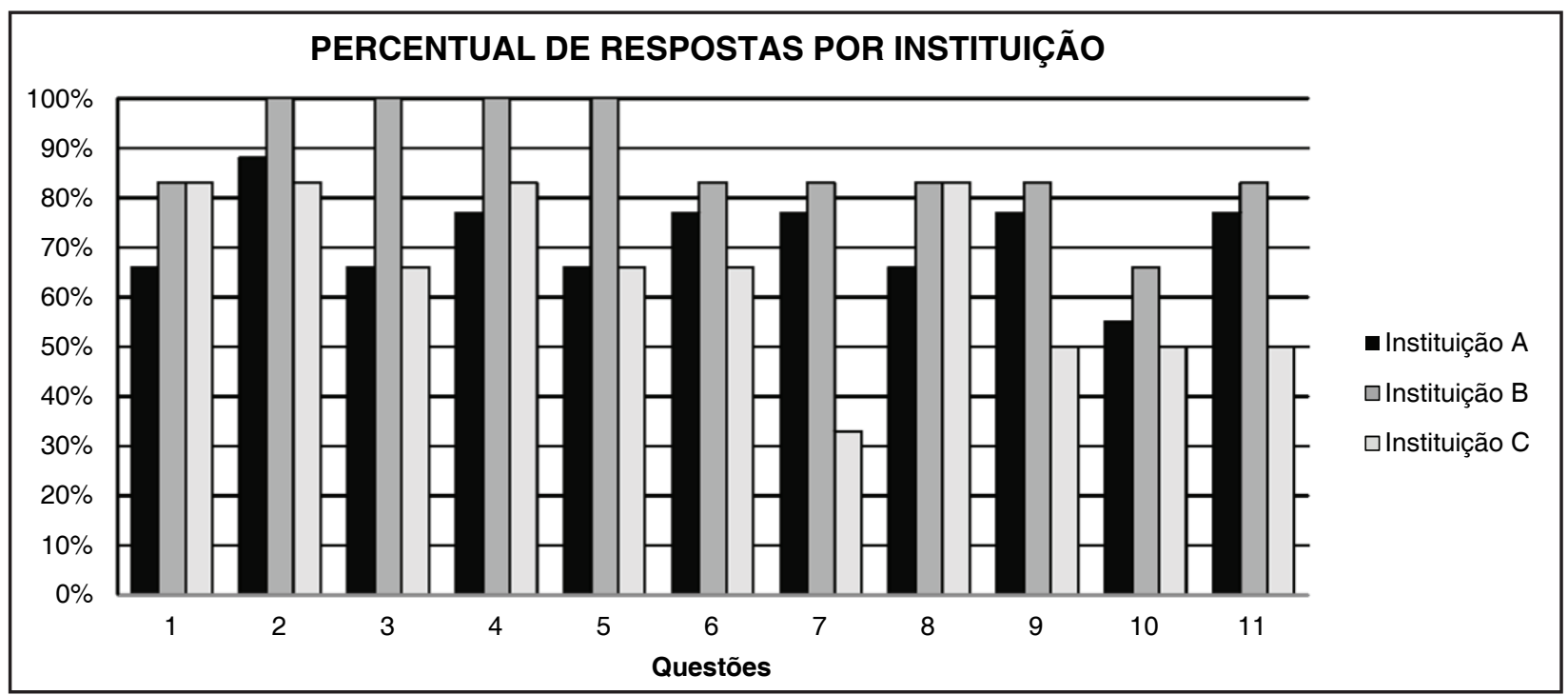

Questões:

1 - Possui curso ou capacitação na área de cuidados com bebê?

2 - Orienta as mães quanto aos cuidados realizados com o bebê?

3 - Orienta as mães quanto aos cuidados pessoais?

4 - Ressalta os benefícios da amamentação exclusiva?

5 - Favorece a participação do pai e/ou familiares na dinâmica dos cuidados pertinentes ao método?

6 - Avalia a evolução da função de alimentação?

7 - Estimula a sucção não- nutritiva?

8 - Estimula a sucção nutritiva?

9- Encaminha para avaliações complementares aqueles que necessitarem de tratamento especializado?*

10 - Encaminha para realização de triagem auditiva neonatal (TAN)?*

11 - Avaliação do estado de consciência e sinais de stress?

*Ressalva-se que tais encaminhamentos não são realizados por toda equipe de saúde, apenas pelos médicos e enfermeiros, no caso da TAN também é realizada pelos fonoaudiólogos.

Figura 4 - Comparação das respostas citadas acima em cada instituição 


\section{Na instituição A (Tabela 1):}

$66 \%$ (6) dos entrevistados declararam possuir curso de capacitação na área de cuidado com bebês. $88 \%$ (8) orientam as mães quanto aos cuidados realizados com o bebê. $66 \%$ (6) orientam as mães quanto aos cuidados pessoais. $77 \%$ (7) ressaltam os benefícios da amamentação exclusiva. $66 \%$ (6) favorecem a participação do pai e/ou familiares na dinâmica dos cuidados pertinentes ao método. $77 \%$
(7) avaliam a evolução da alimentação. 77\% (7) estimulam a sucção não-nutritiva. $66 \%$ (6) estimulam a sucção nutritiva. $77 \%$ (7) encaminham para avaliações complementares os recém-nascidos que necessitarem de tratamento especializado. 55\% (5) encaminham para realização de triagem auditiva neonatal e $77 \%$ (7) avaliam o estado de consciência e sinais de stress.

Tabela 1 - Quadro profissional instituição A

\begin{tabular}{|c|c|c|c|}
\hline Profissão & $\begin{array}{l}\text { Número de } \\
\text { profissionais }\end{array}$ & Vínculo & $\begin{array}{c}\text { Em que etapa do } \\
\text { método está inserido }\end{array}$ \\
\hline Neonatologista & 20 & Concursados e PJ & Todas \\
\hline Obstetra & 1 & Não informado & $1^{\text {a }}$ etapa \\
\hline Oftalmologista & 4 & PJ & Todas \\
\hline Enfermeiro & 15 & Concursados & Todas \\
\hline Auxiliar de enfermagem & $60-70$ & Não informado & Todas \\
\hline Psicólogo & 2 & Concursados & $1^{\mathrm{a}}$ e $2^{\mathrm{a}}$ etapa \\
\hline Fisioterapeuta & 4 & Concursados & Todas \\
\hline Terapeuta ocupacional & 4 & Concursados e PJ & $1^{\mathrm{a}}$ e $2^{\mathrm{a}}$ etapa \\
\hline Assistente social & 4 & Concursados & $1^{\mathrm{a}}$ e $2^{\underline{a}}$ etapa \\
\hline Fonoaudiólogo & 1 & PJ & $1^{\mathrm{a}}$ e $2^{\mathrm{a}}$ etapa \\
\hline Nutricionista & 3 & PJ & $1^{\mathrm{a}}$ e $2^{\mathrm{a}}$ etapa \\
\hline Neuropediatra & 1 & PJ & Todas \\
\hline
\end{tabular}

${ }^{*} \mathrm{PJ}$ : Pessoa Jurídica

Na instituição B (Tabela 2):

$83 \%$ (5) dos entrevistados declararam possuir curso de capacitação na área de cuidado com bebês. $100 \%$ (6) orientam as mães quanto aos cuidados realizados com o bebê. $100 \%$ orientam as mães quanto aos cuidados pessoais. 100\% (6) ressaltam os benefícios da amamentação exclusiva. $100 \%$ (6) favorecem a participação do pai e/ ou familiares na dinâmica dos cuidados pertinentes ao método. $83 \%$ (5) avaliam a evolução da alimentação. $83 \%$ (5) estimulam a sucção não-nutritiva. $83 \%$ (5) estimulam a sucção nutritiva. $83 \%$ (5) encaminham para avaliações complementares aqueles que necessitarem de tratamento especializado. $66 \%$ (4) encaminham para realização de triagem auditiva neonatal e $83 \%$ (5) avaliam o estado de consciência e sinais de stress.
Na instituição C (Tabela 3):

$83 \%$ (5) dos entrevistados declararam possuir curso de capacitação na área de cuidado com bebês. $83 \%$ (5) orientam as mães quanto aos cuidados realizados com o bebê. $66 \%$ (4) orientam as mães quanto aos cuidados pessoais. 83\% (5) ressaltam os benefícios da amamentação exclusiva. $66 \%$ (4) favorecem a participação do pai e/ ou familiares na dinâmica dos cuidados pertinentes ao método. $66 \%$ (4) avaliam a evolução da alimentação. 33\% (2) estimulam a sucção não-nutritiva. $83 \%$ (5) estimulam a sucção nutritiva. $50 \%$ (3) encaminham para avaliações complementares aqueles que necessitarem de tratamento especializado. $50 \%$ (3) encaminham para realização de triagem auditiva neonatal e $50 \%$ (3) avaliam o estado de consciência e sinais de stress. 
Tabela 2 - Quadro profissional instituição B

\begin{tabular}{|c|c|c|c|}
\hline Profissão & $\begin{array}{l}\text { Número de } \\
\text { profissionais }\end{array}$ & Vínculo & $\begin{array}{c}\text { Em que etapa do } \\
\text { método está inserido }\end{array}$ \\
\hline Neonatologista & 27 & Concursado e PJ & Todas \\
\hline Obstetra & Não informado** & Não informado & $1^{a}$ etapa \\
\hline Oftalmologista & 3 & Contratado & Todas \\
\hline Enfermeiro & 15 & Concursado e PJ & Todas \\
\hline Auxiliar de enfermagem & Não informado** & Concursado e PJ & Todas \\
\hline Psicólogo & 1 & Contratado & $1^{\mathrm{a}}$ e $2^{\mathrm{a}}$ etapas \\
\hline Fisioterapeuta & 3 & $\begin{array}{l}\text { Concursado e } \\
\text { contratado }\end{array}$ & Todas \\
\hline Terapeuta ocupacional & 1 & Concursado & Todas \\
\hline Assistente social & 3 & Concursado & Todas \\
\hline Fonoaudiólogo & 1 & Contratado & $2^{\mathrm{a}}$ e $3^{\mathrm{a}}$ etapas \\
\hline Nutricionista & 1 & Concursado & Todas \\
\hline
\end{tabular}

${ }^{*} \mathrm{PJ}$ : Pessoa Jurídica

** Na tabela 4 está representado como zero, porém não foi informado o número de profissionais.

Tabela 3 - Quadro profissional instituição C

\begin{tabular}{|c|c|c|c|}
\hline Profissão & $\begin{array}{l}\text { Número de } \\
\text { profissionais }\end{array}$ & Vínculo & $\begin{array}{c}\text { Em que etapa do } \\
\text { método está inserido }\end{array}$ \\
\hline Neonatologista & 11 & $\begin{array}{l}\text { Concursado, PJ, } \\
\text { Contratado }\end{array}$ & Todas \\
\hline Obstetra & 24 & $\begin{array}{l}\text { Concursado, PJ, } \\
\text { Contratado }\end{array}$ & $1^{\mathrm{a}}$ etapa \\
\hline Oftalmologista & 2 & $\begin{array}{l}\text { Concursado, PJ, } \\
\text { Contratado }\end{array}$ & Todas \\
\hline Enfermeiro & 31 & $\begin{array}{l}\text { Concursado, PJ, } \\
\text { Contratado }\end{array}$ & $1^{a}$ e $2^{\underline{a}}$ etapa \\
\hline Auxiliar de enfermagem & 104 & $\begin{array}{l}\text { Concursado, PJ, } \\
\text { Contratado }\end{array}$ & $1^{\mathrm{a}}$ e $2^{\mathrm{a}}$ etapa \\
\hline Psicólogo & 2 & $\begin{array}{l}\text { Concursado, PJ, } \\
\text { Contratado }\end{array}$ & $1^{\mathrm{a}}$ e $2^{\mathrm{a}}$ etapa \\
\hline Fisioterapeuta & 6 & $\begin{array}{l}\text { Concursado, PJ, } \\
\text { Contratado }\end{array}$ & $1^{\underline{a}}$ e $3^{\underline{a}}$ etapa \\
\hline Terapeuta ocupacional & 0 & & \\
\hline Assistente social & 0 & $\overline{1}$ & 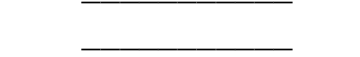 \\
\hline Fonoaudiólogo & 0 & & - \\
\hline Nutricionista & 9 & $\begin{array}{l}\text { Concursado, PJ, } \\
\text { Contratado }\end{array}$ & $1^{\mathrm{a}}$ e $2^{\mathrm{a}}$ etapa \\
\hline
\end{tabular}

${ }^{\star}$ PJ: Pessoa Jurídica 
$\mathrm{Na}$ Tabela 4 evidencia-se o tempo de formação em saúde e o tempo de atuação no método dos especialistas entrevistados nas três instituições.
No que se refere às principais ações realizadas pelos profissionais de saúde em sua rotina no método tem-se os resultados descritos na Figura 5.

Tabela 4 - Variações do tempo de formação em saúde e atuação no MMC

\begin{tabular}{lcc}
\hline Profissional & $\begin{array}{c}\text { Variação do tempo de } \\
\text { formação em saúde }\end{array}$ & $\begin{array}{c}\text { Variação do tempo } \\
\text { de atuação no MMC }\end{array}$ \\
\hline Neonatologista & De 25 a 30 anos & De 5 a 7 anos \\
Oftalmologista & De 22 a 31 anos & De 2 meses a 2 anos \\
Enfermeiro & De 3 a 24 anos & De 1,4 a 6 anos \\
Auxiliar de Enfermagem & De 12 a 34 anos & De 3 meses a 8 anos \\
Fisioterapeuta & De 4 a 30 anos & De 1 a 10 anos \\
Terapeuta ocupacional & De 8 a 10 anos & De 2,6 a 5 anos \\
Fonoaudiólogo & De 9,5 a 30 anos & De 1 a 6 anos \\
Nutricionista & De recém-formado a 23 anos & De recente a 5 anos \\
Neuropediatra & 8 anos & 1 ano \\
\hline
\end{tabular}

\begin{tabular}{|c|c|}
\hline PROFISSIONAL & AÇÕES DE ROTINA NO MMC \\
\hline Neonatologista & $\begin{array}{l}\text { Exame pediátrico completo, orientação às mães quanto à amamentação, } \\
\text { cuidados e importância do método e quanto ao toque no bebê, } \\
\text { posicionamento canguru. }\end{array}$ \\
\hline Oftalmologista & $\begin{array}{l}\text { Avaliação do risco de retinopatia da prematuridade, realização do teste do } \\
\text { reflexo vermelho. }\end{array}$ \\
\hline Enfermeiro & $\begin{array}{l}\text { Aferição do peso diário; posicionamento canguru; proporcionar menor } \\
\text { gasto de energia do RN }\end{array}$ \\
\hline Auxiliar de enfermagem & $\begin{array}{l}\text { Aferição dos sinais vitais, do peso e realização do banho dos neonatos, } \\
\text { oferecimento das medicações, orientação quanto às massagens nas } \\
\text { mamas; posicionamento canguru. }\end{array}$ \\
\hline Fisioterapeuta & $\begin{array}{l}\text { Posicionamento canguru; orientação e capacitação dos profissionais da } \\
\text { unidade quanto aos cuidados relativos ao método; Explicação das } \\
\text { vantagens do método ao genitor; Avaliação do quadro respiratório; Realiza } \\
\text { exercício de alongamento para a mãe. }\end{array}$ \\
\hline Terapeuta ocupacional & $\begin{array}{l}\text { Ênfase sobre a importância do método; Realização de atividades em grupo; } \\
\text { posicionamento canguru. }\end{array}$ \\
\hline Fonoaudiólogo & $\begin{array}{l}\text { Oficinas sobre amamentação; Avaliação das mamas e orientação sobre a } \\
\text { ordenha; orientação à equipe sobre a alimentação dos RN's; Avaliação e } \\
\text { estimulação da sucção não nutritiva para iniciar a transição da sonda para } \\
\text { o peito e avaliação da sucção nutritiva; posicionamento canguru. }\end{array}$ \\
\hline Nutricionista & $\begin{array}{l}\text { Distribuição da formula; ordenha materna; intervenção sobre a alimentação } \\
\text { das mães; conscientização das mães quanto aos benefícios do leite } \\
\text { materno. }\end{array}$ \\
\hline Neuropediatra & $\begin{array}{l}\text { Avaliação do desenvolvimento neuropsicomotor e complicações da } \\
\text { prematuridade e baixo peso. }\end{array}$ \\
\hline
\end{tabular}

Figura 5 - Ações declaradas na rotina dos profissionais de saúde 


\section{DISCUSSÃO}

Devido aos benefícios do método mãe canguru, no ano 2000, o Ministério da Saúde do Brasil aprovou a Norma de Atenção Humanizada ao Recém-Nascido de Baixo Peso (o MMC), recomendando-a e definindo as diretrizes para sua implantação nas unidades médico-assistenciais integrantes do Sistema Único de Saúde (SUS) ${ }^{2}$. Evidencia-se que tal recomendação ainda não é uma realidade em todos os hospitais/ maternidade públicos de Salvador, pois dos sete existentes são quatro os que utilizam o método.

A Norma propõe a aplicação do método em três etapas, iniciando nas unidades de terapia intensiva neonatal (UTIN) e unidades de cuidados intermediários, passando às unidades canguru (ou alojamento conjunto canguru) e, após a alta hospitalar, nos ambulatórios de seguimento (Follow up) ${ }^{2}$. Em Salvador das três instituições pesquisadas, todas declaram realizar as três etapas propostas.

Nos bebês nascidos pré-termos o desenvolvimento que deveria ocorrer ainda intra-útero ficou incompleto, e por este motivo estes bebês muitas vezes, irão precisar da ajuda de uma equipe de vários profissionais para adaptar-se ao seu novo meio: o externo ${ }^{7}$. A norma proposta pelo ministério da saúde prevê ainda que o recém-nascido de baixo peso seja assistido por uma equipe multiprofissional, constituída sempre que possível por: Neonatologistas; obstetras; pediatras; oftalmologista; enfermeiras; auxiliares de enfermagem; psicólogos; fisioterapeutas; terapeutas ocupacionais; assistentes sociais; fonoaudiólogos; nutricionistas².

Quanto ao quadro profissional de cada instituição de Salvador que aplica o MMC evidencia-se que as instituições $A$ e $B$ possuem pelo menos um profissional de cada especialidade recomendada pela norma, no entanto a instituição $C$ não possui terapeuta ocupacional, nem fonoaudiólogo, nem assistente social atuando com os cuidados referentes ao método mãe canguru.

Evidenciou-se ainda que os profissionais de oftalmologia, nutrição e também o fonoaudiólogo em uma das instituições, só comparecem na enfermaria canguru quando solicitados, quando há alguma demanda relativa à sua atuação. Além disso, dão conta das outras demandas de toda a instituição.

A realidade precária de muitos centros de saúde já é de conhecimento público. Em maternidades das regiões menos favorecidas, os Berçários dispõem de poucos recursos de equipamentos, área física restrita, elevado número de recém-nascidos de risco e pequeno número de profissionais da saúde, que por vezes são ainda pouco capacitados ${ }^{8}$. No entanto, a presente pesquisa evidenciou que $76 \%$ do total de entrevistados possuem algum curso ou capacitação na área do cuidado com bebês, o que é positivo para o enfrentamento das condições pouco favoráveis.

No Brasil, o Ministério da Saúde conta com o apoio financeiro do Banco Nacional do Desenvolvimento Econômico e Social (BNDES) para desenvolver a capacitação dos profissionais, a formação de centros de referência nacionais e a produção de material educativo e instrucional ${ }^{2}$.

O quadro de prematuridade e risco de morte para os neonatos resulta em grande conflito para os familiares. A mãe, por exemplo, ao mesmo tempo em que deseja estar ao lado de seu filho luta contra o sentimento de culpa e o medo de não saber cuidar do recém-nascido ${ }^{9,10}$. Por isso é tão relevante a orientação por parte dos profissionais da saúde às mães sobre os cuidados a serem realizados com os neonatos e o método preza que isto aconteça. Nesta pesquisa $90 \%$ dos entrevistados declararam realizar tal orientação.

É também crucial que as mães sejam orientadas quanto aos cuidados pessoais a fim de proporcionar maiores benefícios na díade mãe-bebê ${ }^{1}, 76 \%$ dos entrevistados declararam orientar as mães quanto aos cuidados pessoais, especialmente no que se refere ao cuidado com as mamas.

É aconselhável que haja incentivo, por parte da equipe de saúde, à participação do pai e demais familiares na dinâmica dos cuidados pertinentes ao método ${ }^{2}{ }^{11} .76 \%$ dos entrevistados referiram favorecer tal participação, os que negaram tal atuação apontam para alguns obstáculos, como a questão dos cuidados com a higiene devido ao vestuário destes familiares.

Os recém-nascidos prematuros apresentam uma série de alterações ${ }^{12}$ que podem explicar as dificuldades de sucção e incoordenação com deglutição e respiração, retardando no ganho de peso e, consequentemente, prolongando o tempo de hospitalização. Isto reforçado pela própria imaturidade cerebral que dificulta a permanência em estado de alerta ${ }^{11}$. Por este motivo um dos procedimentos que é preconizado pelo método é o estímulo à sucção por parte dos profissionais da saúde, $66 \%$ dos entrevistados declararam realizar a estimulação da sucção de forma não nutritiva e $76 \%$ de forma nutritiva.

Em virtude das alterações e riscos que os recém nascidos prematuros e de baixo peso estão suscetíveis muitas vezes é necessário encaminhá-los para tratamento especializado e exames complementares ${ }^{13} .71 \%$ dos entrevistados mencionaram encaminhar os RN's para tratamento especializado quando percebem tal necessidade, mas apenas 
57\% referiram encaminhá-los para realização de triagem auditiva neonatal.

Antes do Método Mãe-Canguru, os serviços de atenção neonatal mantinham os prematuros nas incubadoras até alcançarem o peso ideal para alta, esta prática trazia implicações para a mãe e seu filho, tais como: desestímulo ao aleitamento materno; rompimento do vínculo afetivo; tempo de permanência prolongado nas unidades de internamento, entre outros ${ }^{14,11}$. Com a idealização do MMC um dos principais aspectos preconizados é a amamentação exclusiva até os seis meses de vida da criança ${ }^{1,15,11}$, para efetivar essa meta é fundamental o incentivo da equipe de saúde, $85 \%$ dos entrevistados declararam ressaltar os benefícios da amamentação exclusiva aos cuidadores.

Só serão considerados como "Método Canguru" os sistemas que permitam o contato precoce, realizado de maneira orientada, por livre escolha da família, de forma crescente, segura e acompanhado de suporte assistencial por uma equipe de saúde adequadamente treinada ${ }^{2}$. Dentre estes contatos está a posição canguru. A maioria dos especialistas entrevistados declarou que realizar tal posicionamento faz parte de sua rotina diária no método. Apenas três especialidades (oftalmologista, nutricionista, neuropediatra) das nove entrevistadas não declararam realizar tal atuação.

Quanto à atuação do fonoaudiólogo no berçário sabe-se que esta é, na maioria das vezes, desconhecida e pouco solicitada por parte dos profissionais. Isso porque a inserção da fonoaudiologia nesse panorama é recente ${ }^{16}$. Nesta pesquisa observou-se que, das instituições que possuem o método, em duas há fonoaudiólogo, no entanto há apenas um em cada uma. Em uma das instituições há apenas uma fonoaudióloga para toda a instituição e esta só comparece na enfermaria canguru quando solicitada, ou seja, não atua diretamente com o método.

A literatura revela que a Fonoaudiologia deve incorporar-se como uma especialidade para a atenção integral ao bebê e à mãe, com o objetivo de promover os aspectos de aleitamento, alimentação e comunicação global, incluindo o vínculo mãe-bebê, com uma escuta diferenciada e aberta para as dificuldades e diferenças sociais ${ }^{17-21}$.
Quanto às ações realizadas pelos profissionais de saúde na segunda etapa do método, que foram descritas nos resultados, percebe-se que se trata de uma atuação transdisciplinar na qual há uma abordagem científica que visa à unidade do conhecimento. Assim as especialidades trocam informações e conhecimento e trabalham juntas em prol de uma mesma finalidade: o bem estar do neonato e dos cuidadores.

Ou seja, muitas vezes há uma mesma ação sendo desempenhada por todos os profissionais, no entanto cada um tem um olhar específico conforme sua especialidade, porém não se trata de um olhar restringente debruçado somente sobre sua área de conhecimento e sim um olhar global sobre o neonato e seus cuidadores. Desta forma há uma busca por uma nova compreensão da realidade por meio de elementos que passam entre, além e pelas disciplinas, numa busca de compreensão da complexidade.

\section{CONCLUSÃO}

Dos sete hospitais/ maternidade públicos de Salvador quatro utilizam o método mãe canguru. Nos três pesquisados relatou-se a prática das três etapas. Das três instituições, duas possuem quadro profissional com todas as especialidades propostas pela norma do Ministério da Saúde que aprova o método.

Quanto à atuação dos profissionais inseridos na segunda etapa do método percebe-se que esta se incorpora no campo da transdisciplinaridade na qual as diversas especialidades trocam informações e conhecimento visando a unidade.

Dentre as limitações do estudo está o fato de não ter sido possível investigar a utilização do método em todos os hospitais/ maternidades públicos de Salvador, assim fica a sugestão para que novos estudos sejam feitos na área e que todas as instituições sejam abarcadas, bem como estudos comparativos entre as instituições que possuem e as que não possuem o método, a fim de evidenciar a efetividade do método nesta cidade. 


\section{ABSTRACT}

Purpose: to investigate how many public hospitals and maternity hospitals in Salvador use the Kangaroo Mother Method, who are the professionals inserted in the team, and to characterize the acting of the health professionals who are inserted in the second stage of the method. Method: a descriptive quantitative study, in which the persons in charge for the neonatology sector and the health professionals inserted in the second stage of the method took part, answering the questionnaires. The obtained data were analyzed through descriptive statistics where simple frequencies were calculated. Results: four of the seven public institutions of Salvador use the method. All the investigated institutions carry out three preconized stages, in two of them the professional picture has at least an active one of each specialty recommended by the Health Ministry, however reduced number shows up of speech language therapist in the service. Among the principal actions of the health professionals inserted in the second stage are the incentive for a Kangoroo positioning and exclusive breastfeeding and guidance to mothers in caring for the baby. Conclusions: it is proven that the recommendation of the Health Ministry that the method is implanted in the units medical-care integrant of the Sistema Único de Saúde are not yet a reality in all public Hospitals / Maternity Units of Salvador, however we evidenced a professional team in compliance with the recommendation in two of the searched institutions and the performance of the interviewed professionals is incorporated in the field of transdisciplinarity.

KEYWORDS: Hospitals; Hospitals, Maternity; Neonatology

\section{REFERÊNCIAS}

1. Venancio SI, Almeida H. Método Mãe Canguru: aplicação no Brasil, evidências científicas e impacto sobre o aleitamento materno. Jornal Pediatria. 2004; 80:173-80.

2. Brasil. MINISTÉRIO DA SAÚDE. Atenção humanizada ao recém-nascido de Baixo Peso - Método Mãe-Canguru - Manual Técnico, Brasília. 2002.

3. Andrade ISN, Guedes ZCF. Intervenção fonoaudiológica no processo de alimentação em bebês inseridos no método mãe-canguru. Fono Atual. 2005; 8: 13-24.

4. Pettengill MAM, Angelo M. Identificação da vulnerabilidade da família na prática clínica. Rev. Esc. Enferm US 2006; 40: 280-5.

5. Excel-97 [computer program]. Version 2003. USA: Microsoft; 2003.

6. SESAB, secretaria de saúde do Estado da Bahia; Coordenação de Maternidades e Hospitais Especializados - COMAHE, 2009.

7. Lemos ML et al. Assistência ao Recém-Nascido de Risco. 2a Edição, editado por Paulo R. Margotto; 2004.

8. Coordenação de Saúde Materno-Infantil, Ministério da Saúde. Mortalidade perinatal e neonatal. Rev. Assoc. Med. Bras. 1997; 48:4.

9. Bessani et al. Humanizando o atendimento a prematuro em UTI neonatal. Trabalho de Conclusão de Curso da Uniandrade. Rev. de enfermagem 2006. Disponível em: <http://www.uniandrade.edu. br/publicacoes/enfermagem/artigo55.pdf $>$. Acesso: 17 de julho de 2009.
10. Henning MA, Gomes MA, Gianini NO. Conhecimentos e práticas dos profissionais de saúde sobre a "atenção humanizada ao recémnascido de baixo peso - método canguru". Rev Bras Saude Mater Infant. 2006; 6:427-36.

11. Conde-Agudelo A, Diaz-Rossello JL, Belizan JM. Mãe canguru para reduzir morbidade e mortalidade em recém-nascidos com baixo peso ao nascer (Cochrane Review). In: Resumos de Revisões Sistemáticas em Português, Issue 2, 2007.

12. Abrão ACFV. Amamentação uma prática que precisa ser aprendida. Pediatr. 2006; 28: 79-80.

13. Andrade ISN; Guedes ZCF. Sucção do recémnascido prematuro: comparação do método Mãe-Canguru com os cuidados tradicionais. Rev. Bras. Saude Mater. Infant. 2004; 11:1-5.

14. Costa CN, Lima GRS, Jorge RM, Malta RACG, Nemr K. Efetividade da intervenção fonoaudiológica no tempo da intervenção de alta hospitalar do recém-nascido pré-termo. Rev CEFAC 2007; 9: $72-8$.

15. Ishii C, Miranda CS, Isotani SM, Perissinoto J. Caracterização de comportamentos lingüísticos de crianças nascidas prematuras, aos quatro anos de idade. Rev CEFAC. 2006; 8: 147-54.

16. Freitas JO, Camargo CL. Método Mãe-Canguru: evolução ponderal de recém-nascidos. Acta paul. Enferm. 2007; 20: 75-81.

17. Conselho Regional de Fonoaudiologia São Paulo. Aleitamento materno. [periódico online] 2007. Disponível em: http://www.fonosp.org.br/ publicar/conteudo.php?id=646 . 
18. Neivas FCB, Leone CR. Evolução do ritmo de sucção e influência da estimulação em prematuros. Pró-Fono. 2007; 19: 241-8.

19. Rocha MS, Delgado SL. Intervenção fonoaudiológica em recém-nascido pré-termo com gastrosquise. Rev Soc Bras Fonoaudiol.2007; 12:55-62.
20. Alves AML, Silva EHAA, Oliveira AC. Desmame precoce em prematuros participantes do Método Mãe Canguru. Rev Soc Bras Fonoaudiol. 2007; 12: 3-8.

21. Andreani, G., Custodio, Z. A. O. \& Crepaldi, M. A. Tecendo as redes de apoio na prematuridade. Aletheia. 2006; 24:115-26.

RECEBIDO EM: 16/02/2010

ACEITO EM: 07/08/2010

Endereço para Correspondência:

Universidade Federal da Bahia, Instituto

de Ciências da Saúde, Departamento de

Fonoaudiologia

Juliana Rodrigues da Silva

Av. Reitor Miguel Calmon, $s / n$ - Vale do Canela

Salvador - BA

CEP: 40110-902

E-mail: Juliana_rsilva@ $@$ hotmail.com 